\title{
Uréia para Vacas Leiteiras no Pós-Parto: Teor Plasmático de Uréia e pH Uterino ${ }^{1}$
}

\author{
Margarida Maria Nascimento Figueiredo de Oliveira², Ciro Alexandre Alves Torres ${ }^{3}$, \\ Eduardo Paulino da Costa ${ }^{4}$, Giovanni Ribeiro de Carvalho ${ }^{5}$
}

\begin{abstract}
RESUMO - O objetivo deste trabalho foi verificar os efeitos de níveis crescentes de uréia nas dietas de vacas leiteiras no pós-parto sobre os teores plasmáticos de N-uréia (NUP) e o pH uterino no estro e na fase luteal. Utilizaram-se dezesseis vacas mestiças (Holandêszebu) com escore corporal ao parto entre 3,5 e 4,0 (escala 1 a 5), que foram alocadas em quatro tratamentos constituídos de dietas contendo volumoso (silagem de milho) e concentrado, na proporção 60:40: $\mathrm{T}_{1}=0,0 ; \mathrm{T}_{2}=0,7 ; \mathrm{T}_{3}=1,4 ;$ e $\mathrm{T}_{4}=2,1 \%$ de uréia na matéria seca total. No estro e na fase luteal, do segundo ou terceiro ciclo estral pós-parto, realizou-se a medição do pH uterino quatro horas após o fornecimento da dieta e; simultaneamente foram coletadas amostras de sangue para determinação dos teores plasmáticos de uréia. A ingestão de matéria seca dos 70 aos 110 dias de lactação reduziu a partir do nível 0,7\% de uréia e a produção de leite não foi influenciada pelos níveis de uréia das dietas. Não houve influência dos níveis de uréia sobre os teores plasmáticos de N-uréia, em amostras de sangue coletadas no estro, que foram, em média, de $19,59 \mathrm{mg} / \mathrm{dL}$. O pH uterino no estro $(6,66)$ e na fase luteal $(6,97)$ também não foi influenciado pelos diferentes níveis de uréia nas dietas.
\end{abstract}

Palavras-chave: bovinos, compostos nitrogenados-não protéicos, reprodução

\section{Urea for Dairy Cows in the Postpartum: Urea Levels in the Plasma and Uterine pH}

ABSTRACT - The objective of this work was to evaluate the effects of increasing levels of urea in the diets in postpartum crossbred dairy cows on plasma level of N-urea (NUP) and uterine pH in the estrus and luteal phase. Sixteen crossbred cows (Holstein-zebu) with body condition score at parturition between 3.5 and 4.0 ( 1 to 5 scale) were assigned in four treatments with diets made up with corn silage and concentrate in the proportion of $60: 40$ as: $\mathrm{T}_{1}=0.0 ; \mathrm{T}_{2}=0.7 ; \mathrm{T}_{3}=1.4 ;$ and $\mathrm{T}_{4}=2.1 \%$ of urea in the dry matter. The uterine $\mathrm{pH}$ was measured four hours after the diet intake, during the estrus and luteal phase from the second or third estrous cycle postpartum period in dairy cows. Simultaneously, blood samples were collected for determination of the level of plasma urea. The dry matter intake from 70 to 110 days of lactation reduced from $0.7 \%$ of urea. The levels of plasma $\mathrm{N}$ urea were not affected in the samples collected during the estrus (19.59 mg/dL). The uterine pH during estrus (6.66) and luteal phase (6.97) were not affected by the different levels of urea.

Key Words: cattle, non-protein nitrogen, reproduction

\section{Introdução}

O ambiente uterino é dinâmico e apresenta diferenças nas fases do ciclo estral, devido à regulação esteroidogênica dos ovários e a secreção endometrial (Butler, 2000), sendo que o pH e a concentração iônica da secreção uterina durante a fase luteal podem ser influenciados pela ingestão de dietas contendo elevados teores de proteína, provocando redução da fertilidade de vacas leiteiras no pós-parto (Butler, 1998).

Os efeitos diretos do $\mathrm{pH}$ uterino na sobrevivência embrionária nas espécies domésticas ainda não são totalmente conhecidos. Elrod et al. (1993) verificaram que o $\mathrm{pH}$ uterino é inversamente relacionado aos teores de N-uréia plasmática (NUP) e que ocorre redução específica do $\mathrm{pH}$ durante a fase luteal, sugerindo que o comprometimento da fertilidade seja resultado de alterações dos efeitos da progesterona, no microambiente uterino, gerando condições subótimas para o desenvolvimento embrionário.

Butler (1998) observou que teor de NUP acima de $19 \mathrm{mg} / \mathrm{dL}$ foi associado à redução da concentração plasmática de progesterona e alteração do $\mathrm{pH}$ e ambiente uterino, constituindo as principais causas de redução da fertilidade de vacas leiteiras no início da

\footnotetext{
1 Parte da tese de Doutorado apresentada à Universidade Federal de Viçosa. Projeto parcialmente financiado pela CAPES

2 Professora do DZO/FAFEID, Diamantina - MG. E.mail: margarida@fafeid.edu.br

3 Professor do DZO/ UFV. Bolsista CNPq. E.mail: ctorres@ufv.br

4 Professor do DVT/UFV.

5 Professor do DZO/UFV.
} 
lactação. Segundo Sinclair et al. (2000), dietas contendo excesso de PDR ou NNP podem aumentar os níveis plasmáticos de amônia e uréia, sendo que os efeitos na fertilidade possivelmente sejam mediados pela uréia, que é uma molécula relativamente estável nos fluidos orgânicos

Considerando que as recomendações tradicionais para a utilização de uréia em rações de ruminantes com valores de no máximo $40 \mathrm{~g}$ de uréia para cada $100 \mathrm{~kg}$ de peso vivo, objetivou-se verificar os efeitos de níveis crescentes de uréia nas dietas de vacas leiteiras no pós-parto sobre os teores de NUP e o pH uterino no estro e na fase luteal.

\section{Material e Métodos}

O experimento foi realizado na Fazenda Experimental EPAMIG, localizada no município de Leopoldina-MG. Foram utilizadas 16 vacas mestiças (Holandês/zebu) com escore corporal ao parto entre 3,5 e 4,0, adotando-se escala de 1 a 5 ( $1=$ muito magra; 5 = gorda), distribuídas aleatoriamente e eqüitativamente em quatro tratamentos constituídos por dietas isoprotéicas, que continham $\mathrm{T}_{1}=0,0$; $\mathrm{T}_{2}=0,7 ; \mathrm{T}_{3}=1,4 ;$ e $\mathrm{T}_{4}=2,1 \%$ de uréia.

À abertura de cada silo, foram retiradas amostras para determinação do teor de matéria seca da silagem de milho e cálculo das quantidades de volumoso e concentrado de cada dieta, obedecendo à proporção de 60:40, previamente estabelecida.

Consta na Tabela 1 a composição porcentual dos ingredientes das dietas.

A ingestão de matéria seca (MS) foi estimada com base no consumo de matéria natural dos 70 aos 110 dias de lactação. O consumo de matéria natural foi obtido diariamente por meio da diferença entre o alimento fornecido e a sobra recolhida e pesada antes do fornecimento de nova dieta, admitindo-se que as sobras tinham o mesmo teor de MS do alimento fornecido. Foram utilizados valores de 40,44\% e $42,15 \%$ para os teores de MS da silagem de milho e $88,3 \%$ dos concentrados, respectivamente.

As partes de volumoso e concentrado na proporção 60:40, previamente estabelecidas, foram determinadas por meio da razão entre a proporção de cada alimento e seu respectivo teor de matéria seca. A ingestão de matéria seca estimada resultou da soma do porcentual de partes do volumoso e do concentrado multiplicadas por seus respectivos conteúdos de matéria seca, menos a sobra.
Foram realizadas medições do $\mathrm{pH}$ intra-uterino, no estro (dia 0) e na fase luteal (dia 7) do segundo ou terceiro ciclo estral no pós-parto, desde que tivesse transcorridos no mínimo 90 dias no pós-parto. Com auxílio de uma pipeta para infusão uterina descartável, injetaram-se, por via intracervical, $60 \mathrm{~mL}$ de água destilada e deionizada, nos cornos uterinos. Após 30 segundos de massageamento, coletou-se o líquido por meio de aspiração e mediu-se o pH utilizando-se um peagâmetro digital, marca Analyser, modelo pH 200, acoplado a um eletrodo de $\mathrm{pH}$ e com capacidade de medição de $\mathrm{pH}$ de 0 a 14.

Após a aspiração do líquido, os cornos uterinos foram novamente massageados para retirar o excesso. As medições foram realizadas sempre quatro horas após o fornecimento da dieta, e o equipamento foi previamente calibrado com soluções tampão para $\mathrm{pH}$ 4 e 7 e ajuste de temperatura ambiente.

Imediatamente após medição do $\mathrm{pH}$ intra-uterino no estro, foram coletadas amostras de sangue para determinação dos teores plasmáticos de uréia. As amostras foram coletadas em tubos de vidro vacuolizados contendo anticoagulante EDTA (K3), por meio de punção da artéria ou veia coccígea, transportadas em caixas de isopor com gelo e centrifugadas a $5.000 \mathrm{rpm}$, durante 20 minutos. $\mathrm{O}$ plasma obtido foi conservado a $-20^{\circ}$ até a sua análise. As amostras foram analisadas, pelo método diacetil modificado, no Laboratório de Fisiologia Animal do Departamento de Medicina Veterinária da Universidade Federal de Viçosa.

Tabela 1 - Composição percentual dos ingredientes utilizados nos tratamentos experimentais (\% na MS)

Table 1 - Percent composition of ingredients used in the experimental treatments (\%DM)

\begin{tabular}{|c|c|c|c|c|}
\hline \multirow{2}{*}{$\begin{array}{l}\text { Ingredientes } \\
\text { Ingredients }\end{array}$} & \multicolumn{4}{|c|}{$\begin{array}{l}\text { Tratamentos } \\
\text { Treatments }\end{array}$} \\
\hline & 1 & 2 & 3 & 4 \\
\hline $\begin{array}{l}\text { Silagem de milho } \\
\text { Corn silage }\end{array}$ & 60 & 60 & 60 & 60 \\
\hline $\begin{array}{l}\text { Fubá de milho } \\
\text { Corn meal }\end{array}$ & 18,31 & 22,19 & 26,07 & 29,95 \\
\hline $\begin{array}{l}\text { Farelo de soja } \\
\text { Soybean mean }\end{array}$ & 20,09 & 15,51 & 10,93 & 6,35 \\
\hline $\begin{array}{l}\text { Uréia } \\
\text { Urea }\end{array}$ & 0,00 & 0,70 & 1,40 & 2,10 \\
\hline $\begin{array}{l}\text { Mistura mineral } \\
\text { Mineral mix }\end{array}$ & 1,60 & 1,60 & 1,60 & 1,60 \\
\hline
\end{tabular}


Todos os animais foram inseminados ao final do terceiro ciclo estral no pós-parto e o diagnóstico de gestação, realizado após 60 dias por meio de palpação transretal.

Os resultados foram avaliados por meio de análises de variância e regressão, utilizando-se o programa SAEG - Sistema de Análises Estatísticas e Genéticas (UFV, 1998).

\section{Resultados e Discussão}

Na Tabela 2, podem ser observadas as médias diárias da ingestão de matéria seca e da produção de leite dos 70 aos 110 dias de lactação.

A ingestão de matéria seca reduziu $(\mathrm{P}<0,01)$ a partir do nível $0,7 \%$ de uréia na dieta, sendo a máxima ingestão de matéria seca obtida com $0,52 \%$ de uréia na ração, fato que pode ser atribuído aos efeitos metabólicos da uréia e, ou, à baixa palatabilidade do alimento, caracterizada pelo seu sabor amargo. Outro aspecto observado, que provavelmente contribuiu para redução do consumo de matéria seca, foi o peso específico e a granulometria da uréia, que podem ter favorecido a segregação do alimento, permitindo que, mesmo com o fornecimento da dieta na forma de mistura completa, a uréia fosse refugada em maior quantidade, nos níveis de 1,4 e $2,1 \%$, ocasionando maiores sobras diárias.

Wilson et al. (1975) estudaram o efeito de níveis crescentes de uréia, independentemente do modo de fornecimento, observando-se que níveis de uréia

Tabela 2 - Médias da ingestão de matéria seca (IMS) e da produção de leite (PL), em $\mathrm{kg} / \mathrm{dia}$, em função dos níveis de uréia nas dietas, obtidas dos 70 aos 110 dias de lactação e probabilidades $(P)$ referentes aos efeitos linear $(L)$ e quadrático $(\mathrm{Q})$

Table 2 - Average dry matter intake (DMI) and milk production (MP), in $\mathrm{kg} /$ day, according to the dietary urea levels, from 70 to 110 days of lactation, and probabilities $(P)$ in relation to the linear $(L)$ and quadratic (Q) effects

\begin{tabular}{|c|c|c|c|c|c|c|}
\hline & \multicolumn{4}{|c|}{$\begin{array}{c}\text { Níveis de uréia (\%) } \\
\text { Urea levels (\%) }\end{array}$} & \multicolumn{2}{|c|}{$\mathrm{P}$} \\
\hline & 0,0 & 0,7 & 1,4 & 2,1 & $\mathrm{~L}$ & Q \\
\hline IMS & & & & & & \\
\hline $\begin{array}{l}D M I \\
\text { PL }\end{array}$ & 15,78 & 18,88 & 13,57 & 9,07 & 0,0270 & 0,0012 \\
\hline$M P$ & 16,90 & 18,13 & 17,64 & 14,26 & NS & NS \\
\hline
\end{tabular}

acima de $2 \%$ reduziram o consumo de matéria seca, sugerindo que os metabólitos intermediários do catabolismo da uréia podem, em parte, ser os responsáveis pela redução na ingestão de alimentos, quando os níveis de uréia na ração total estão acima de 1\%. Já Huber (1984) considera que os mecanismos envolvidos na redução do consumo, provenientes da ingestão de uréia, podem estar relacionados à rejeição pelo paladar, e não a eventos ruminais ou pós-ruminais.

Com relação ao nível de produção de leite e ao estádio da lactação, observa-se na Tabela 2 que não houve efeito $(\mathrm{P}>0,05)$ dos níveis de uréia nas dietas sobre as médias da produção de leite, dos 70 aos 110 dias de lactação. Todavia, Oliveira et al. (2001) verificaram redução linear na produção de leite com o aumento dos níveis de compostos nitrogenados-não protéicos (NNP), quando utilizaram as mesmas rações para vacas com média de produção de leite um pouco mais elevada $(18,87 \mathrm{~kg} / \mathrm{dia})$ que a observada na presente pesquisa.

$\mathrm{Na}$ Tabela 3, estão apresentadas as médias do pH uterino no estro e no sétimo dia do ciclo estral (fase luteal) e os teores de N-uréia plasmática (NUP), em função dos níveis de uréia nas dietas, os coeficientes de variação e o nível de probabilidade dos efeitos linear e quadrático.

Não houve influência $(\mathrm{P}>0,05)$ dos níveis de uréia nas dietas sobre os teores de NUP, cuja média geral obtida em amostras de sangue coletadas no estro foi de $19,59 \mathrm{mg} / \mathrm{dL}$. Estes resultados podem ser atribuí-

Tabela 3 - Médias do pH uterino no estro (pHE), no sétimo dia do ciclo estral ( $\mathrm{pHL}$ ) e dos teores de $\mathrm{N}$-uréia plasmáticos (NUP), em $\mathrm{mg} / \mathrm{dL}$, em função dos níveis de uréia (\%) das rações, coeficiente de variação (CV) e probabilidades $(P)$ referentes aos efeitos linear $(L)$ e quadrático $(\mathrm{Q})$

Table 3 - Average uterine $\mathrm{pH}$ at estrous ( $\mathrm{pHE}$ ), at $7^{\text {th }}$ day of estrous cycle, and level of plasma $\mathrm{N}$-urea (NUP), in $\mathrm{mg} / \mathrm{dL}$, according to the dietary urea levels, coefficients of variation (CV) and probabilities $(P)$ in relation to the linear $(L)$ and quadratic (Q) effects

\begin{tabular}{|c|c|c|c|c|c|c|c|}
\hline & \multicolumn{4}{|c|}{$\begin{array}{c}\text { Níveis de uréia (\%) } \\
\text { Urea levels (\%) }\end{array}$} & \multirow[t]{2}{*}{$\begin{array}{l}\mathrm{CV} \\
(\%)\end{array}$} & \multicolumn{2}{|c|}{$\mathrm{P}$} \\
\hline & 0,0 & 0,7 & 1,4 & 2,1 & & $\mathrm{~L}$ & Q \\
\hline$\overline{\mathrm{pHE}}$ & 6,53 & 6,67 & 6,81 & 6,64 & 5,48 & $\mathrm{~N}$ & $\mathrm{NS}$ \\
\hline $\mathrm{pHL}$ & 7,13 & 6,73 & 6,97 & 6,98 & 6,64 & NS & NS \\
\hline NUP & 21,05 & 18,25 & 20,84 & 17,91 & 38,53 & NS & NS \\
\hline
\end{tabular}


dos ao fornecimento de dietas isoprotéicas.

Os resultados obtidos são próximos ao limiar de compatibilidade aos aspectos reprodutivos proposto por Elrod \& Butler (1993), Elrod et al. (1993), Butler et al. (1996), os quais verificaram que níveis de NUP acima de 19 a $20 \mathrm{mg} / \mathrm{dL}$ reduziram a fertilidade e as taxas de concepção de vacas leiteiras e novilhas.

Segundo Elrod (1992), os teores de uréia no plasma e no leite são reflexos da ingestão de proteína, da degradabilidade das fontes protéicas e da energia disponível no rúmen e apresentam correlação negativa com a fertilidade, sendo que níveis acima de $16 \mathrm{mg} / \mathrm{dL}$ acarretaram redução de $30 \%$ na taxa de concepção de novilhas ao primeiro serviço. A análise dos dados de vacas em lactação mostrou nível crítico de NUP de $19 \mathrm{mg} / \mathrm{dL}$, acima do qual foi observada significativa redução da fertilidade, confirmando os achados de Ferguson et al. (1988), que verificaram redução das taxas de gestação em vacas com NUP acima de $20 \mathrm{mg} / \mathrm{dL}$. Canfield et al. (1990) também observaram que animais com NUP acima de $18,57 \mathrm{mg} / \mathrm{dL}$ apresentaram menores taxas de gestação.

Butler (1998) verificou que teores de NUP maiores que $19 \mathrm{mg} / \mathrm{dL}$ estavam associados a alterações no $\mathrm{pH}$ e modificações no ambiente uterino, sendo essa a principal causa da redução da fertilidade de vacas leiteiras no pós-parto. No presente experimento, a média dos teores de NUP foi de $19,59 \mathrm{mg} / \mathrm{dL}$ e não houve alteração no $\mathrm{pH}$ uterino decorrente da substituição do farelo de soja pela uréia nos níveis testados.

$\mathrm{O}$ pH uterino no estro não foi influenciado $(\mathrm{P}>0,05)$ pelos níveis de uréia nas dietas. Resultado semelhante foi obtido por Elrod et al. (1993), que também não verificaram diferença significativa entre médias de $\mathrm{pH}$ uterino no estro, para vacas consumindo dietas balanceadas $(6,83)$, contendo excesso de proteína não degradável no rúmen (PNDR) $(6,81)$ ou excesso de proteína degradável no rúmen (PDR) $(6,84)$, sugerindo que a ingestão de quantidades excessivas de proteína, independentemente de sua degradabilidade, não provoca alterações do $\mathrm{pH}$ uterino nessa fase do ciclo estral.

Segundo Elrode Butler (1993), alterações fisiológicas que ocorrem durante o estro podem ser atribuídas a maiores concentrações circulantes do estradiol e conseqüente aumento do anabolismo, e não à redução do consumo de matéria seca dos animais durante o estro.

A média geral do $\mathrm{pH}$ obtida no presente experimento foi de 6,66 e 6,97 no estro e diestro, respecti- vamente, sendo que $\mathrm{pH}$ uterino mais alto na diestro também foi observado por Elrod et al. (1993), que consideraram essa diferença, uma condição fisiológica da fase luteal, resultante do aumento dos teores de $\mathrm{Na}^{+}, \mathrm{K}^{+}, \mathrm{P}^{-}$e também da anidrase carbônica, decorrentes da ação da progesterona.

Como pode ser observado na Tabela 3 , o pH uterino no sétimo dia do ciclo estral não foi influenciado $(\mathrm{P}>0,05)$ pelos níveis de uréia nas dietas. Elrod \& Butler (1992), citados por Elrod (1992), utilizando carúnculas endometriais dissecadas do útero de vacas e novilhas no diestro, após 4 horas de perfusão com uréia $(25 \mathrm{mg} / \mathrm{dL})$ ou amônia $(5 \mathrm{mg} / \mathrm{dL})$, verificaram que independentemente do tratamento, as concentrações de $\mathrm{Mg}^{++}, \mathrm{Ca}^{++}, \mathrm{Cl}^{-}, \mathrm{Na}^{+}$e $\mathrm{HCO}^{-}$foram maiores na serosa, enquanto as de $\mathrm{P}^{-}$e $\mathrm{K}^{+}$foram mais elevadas na mucosa, resultando em uma medida de $\mathrm{pH}$ aproximadamente 0,19 unidades mais baixo que na serosa. A amônia alterou significativamente $\mathrm{o}$ fluxo de $\mathrm{Na}^{+}$e $\mathrm{K}^{+}$via endométrio, e a uréia reduziu significativamente o $\mathrm{pH}$ na mucosa e alterou o transporte de $\mathrm{P}^{-}, \mathrm{K}^{+}$e $\mathrm{Na}^{+}$, evidenciando que uréia e amônia influenciaram, por meio de mecanismos diferentes, o processo de transporte iônico no endométrio, resultando em alterações do ambiente uterino, principalmente na mucosa, o que pode ser prejudicial ao desenvolvimento do concepto. Possivelmente, a redução do $\mathrm{pH}$ uterino foi mediada por um sinal metabólico, reconhecido especificamente pela mucosa endometrial, gerando alteração no gradiente de concentração de $\mathrm{P}^{-}, \mathrm{K}^{+}$e $\mathrm{Na}^{+}$e, conseqüentemente, atraindo íons hidrogênio.

Embora na presente pesquisa não tenham sido determinados os teores de uréia no fluido endometrial, nas diferentes fases do ciclo estral, o fornecimento de dietas isoprotéicas variando apenas os níveis de uréia em substituição ao farelo de soja, que se constituem fontes de NNP e PDR, respectivamente, resultou em pequena variação no teor plasmático de $\mathrm{N}$-uréia. Possivelmente, seja este o principal sinal metabólico para a redução no $\mathrm{pH}$ uterino durante a fase luteal, permitindo inferir que os níveis de uréia testados na dieta não alteraram o $\mathrm{pH}$ uterino na fase luteal.

Elrod \& Butler (1993) forneceram a novilhas virgens dietas formuladas para ingestão de $70 \%$ das exigências de energia metabolizável, sendo que em um tratamento as exigências protéicas foram excedidas em $50 \%$ (alta proteína). Esses autores verificaram que, no dia 7 do ciclo estral, o pH uterino foi significativamente menor $(6,79)$ no grupo com alta proteína, quando comparado ao grupo recebendo 
dieta com as exigências de proteína $(7,09)$, sugerindo que o efeito de dietas com alta ingestão de proteína influencia o $\mathrm{pH}$ uterino somente na fase luteal, o que não foi observado neste experimento, no qual foram utilizadas dietas isoprotéicas, variando os teores de NNP nas dietas.

\section{Conclusões}

O aumento dos níveis de uréia nas rações não teve efeito nos teores de NUP e no $\mathrm{pH}$ uterino no estro e na fase luteal.

\section{Literatura Citada}

BUTLER, W.R. Effect of protein nutrition on ovarian and uterine physiology in dairy cattle. Journal of Dairy Science, v.81, n.9, p.2533-2539, 1998.

BUTLER, W.R. Nutritional interactions with reproductive performance in dairy cattle. Animal Reproduction Science, v.60- 61, p.449-457, 2000.

BUTLER, W.R.; CALAMAN, J.J.; BEAM, S.W. Plasma and milk urea nitrogen in relation to pregnancy in lactating dairy cattle. Journal of Animal Science, v.74, n.4, p.858-865, 1996.

CANFIELD, R.W.; SNIFFEN, C.J.; BUTLER, W.R. Effects of excess degradable protein on postpartum reproduction and energy balance in dairy cattle. Journal of Dairy Science, v.73, n.9, p.2343-2349, 1990.

ELROD, C.C. High dietary protein and high fertility: can we have both? Cornell Nutrition Conference Proceedings, p.32-37, 1992.

ELROD, C.C.; BUTLER, W.R. Reduction of fertility and alteration of uterine $\mathrm{pH}$ in heifers fed excess ruminally degradable protein. Journal of Animal Science, v.71, n.4, p.694-701, 1993.
ELROD, C.C.; Van AMBURG, M.; BUTLER, W.R. Alterations of $\mathrm{pH}$ in response to increased dietary protein in cattle are unique to the uterus. Journal of Animal Science, v.71, n.3, p.702-706, 1993.

FERGUSON, J.D.; BLANCHARD, T.; GALLIGAN, D.T. et al. Infertility in dairy cattle fed high percentage of protein degradable in the rumen. JAVMA, v.192, n.5, p.659-662, 1988.

HUBER, J.T. Uréia ao nível do rúmen. In: SIMPÓSIO SOBRE NUTRIÇÃO DE BOVINOS, 2., 1984, Piracicaba. Anais... Piracicaba: Fundação de Estudos Agrários Luiz de Queiroz, 1984. p.25-79.

OLIVEIRA, A.S.; VALADARES, R.F.D.; VALADARES FILHO, S.C. et al. Consumo, digestibilidade aparente, produção e composição do leite de vacas alimentadas com quatro níveis de compostos nitrogenados não-protéicos. Revista Brasileira de Zootecnia, v.30, n.4, p.1358-1366, 2001.

SINCLAIR, K.D.; KURAN, M.; GEBBIE, F.E. et al. Nitrogen metabolism and fertility in catle: II. Development of oocytes recovered from heifers offered diets differing in their rate of nitrogen release in the rumen. Journal of Animal Science, v.78, n.10, p.2670-2680, 2000.

UNIVERSIDADE FEDERAL DE VIÇOSA-UFV.- Sistema de análises estatísticas e genéticas- SAEG. Viçosa: Universidade Federal de Viçosa,1998. (Versão 8.0).

WILSON, G.; MARTZ, F. A.; CAMPBELL, J.R. et al. Evaluation of factors responsible for reduced voluntary intake of urea for ruminants. Journal of Animal Science, v.41, n.5, p.1431-1437, 1975. 